\title{
Mineração
}

\section{Aspectos e impactos ambientais de pedreira em área urbana}

\author{
Denise de La Corte Bacci \\ Pesquisadora da Embrapa Monitoramento por Satélite \\ Av. Dr. Júlio Soares de Arruda, 803, Parque São Quirino, 13088-300 - Campinas - SP \\ E-mail:bacci@cnpm.embrapa.br
}

Paulo Milton Barbosa Landim

Depart. de Geologia Aplicada. Instituto Geociências e Ciência Exatas - UNESP Av. 24A, 1515, Bairro Bela Vista - Rio Claro - SP. E-mail:plandim@rc.unesp.br

Sérgio Médici de Eston

Depart. de Engenharia de Minas e de Petróleo. Escola Politécnica da Universidade de São Paulo (EPUSP) Av. Mello Moraes, 2393, Cidade Universitária, São Paulo - SP. E-mail: smeston@usp.br

\section{Resumo}

O conceito de desempenho ambiental tem sido utilizado como forma para revelar as relações da empresa com o meio ambiente e com a sociedade, constituindo um parâmetro de análise da sua postura diante das questões sócio-ambientais. A avaliação dos aspectos e impactos ambientais gerados por determinada atividade é um instrumento da gestão ambiental, sendo aplicado, nesse trabalho, em uma pedreira de diabásio, na área de expansão urbana, no município de Campinas (SP). Foram avaliados os aspectos e impactos das etapas produtivas da pedreira e de suas instalações administrativas. Os impactos adversos mais significativos levantados foram a sobrepressão atmosférica e a vibração do terreno, causando desconforto à comunidade. Após tais levantamentos, algumas ações de melhoria foram implantadas pela empresa e resultaram na diminuição das reclamações por parte da comunidade; outras medidas, pró-ativas, devem ainda ser implementadas, principalmente aquelas voltadas para a prevenção de impactos negativos e a preservação do meio ambiente, além da recuperação da área degradada, como medida reativa.

Palavras-chave: impactos ambientais, pedreira de diabásio, desempenho ambiental.

\begin{abstract}
The concept of environmental performance has been used as a way of revealing the relationships of a company with its environment and community, and is a parameter of its posture in addressing social and environmental questions. Evaluation of the environmental impacts generated by a certain activity is one instrument of environmental management. We present a case study of a diabase quarry located in an expanding urban area in the Municipality of Campinas, State of São Paulo, Brazil. Several aspects and impacts of the different stages of production in the quarry, as well as its administrative facilities, were evaluated. The most significant adverse impacts were airblast and ground vibration disturbing the neighborhood. After the environmental monitoring, some ameliorative actions were implemented and have resulted in reduction of claiming; new pro-active attitudes could be initiated by the company mostly related to prevention of negative impacts, environmental preservation, and reclamation of the quarry site, as a reactive posture.
\end{abstract}

Keywords: environmental impacts, diabase quarry, environmental performance. 


\section{Introdução}

O conhecimento e a divulgação dos aspectos ambientais de um empreendimento atendem às expectativas de uma melhoria no desempenho ambiental (ISO 14.001:1996, ABNT, 1996; ISO 14.031, 1999; De Jorge, 2001). Conhecendo-se, previamente, os problemas associados à implantação e operação do empreendimento, por meio de instrumentos de avaliação de impacto e planejamento ambientais, pode-se adotar medidas que evitem ou atenuem tais impactos, reduzindo os danos ambientais e, conseqüentemente, os custos envolvidos na sua remediação ou correção.

Para a identificação dos aspectos e avaliação dos impactos ambientais associados a determinado empreendimento, deve-se procurar, inicialmente, selecionar todas as atividades, produtos e serviços relacionados à atividade produtiva, de modo a separar o maior número possível de impactos ambientais gerados, reais e potenciais, benéficos e adversos, decorrentes de cada aspecto identificado, considerando, sempre, se são significativos ou não (Sánchez, 2001).

Segundo De Jorge (2001), o processo completo de avaliação do desempenho ambiental, realizado em uma base contínua e de forma sistemática e periódica, permite às empresas verificar se os seus objetivos estão sendo atingidos, além de fornecer um mecanismo para investigar e apresentar informações confiáveis e verificáveis, inclusive de natureza financeira, que podem ser relatadas às partes interessadas, por exemplo, acionistas e usuários, órgãos financiadores, fiscalizadores e ambientais.

O presente estudo identifica os aspectos e avalia os impactos ambientais gerados por uma pedreira de diabásio usado como agregado na construção civil, inserida em área urbana no município de Campinas, Estado de São Paulo.
2. Impactos ambientais na exploração mineral

A proximidade de pedreiras de centros habitados é uma decorrência natural da forte influência do custo dos transportes no preço final do produto. Isso ocorre, principalmente, com os agregados, devido ao seu baixo valor unitário. Os fatores geológicos ligados à localização natural da jazida e ao grande volume das reservas, proporcionando longa vida útil aos empreendimentos, são fatores rígidos e imutáveis que impedem a mudança das áreas de extração.

Por outro lado, o crescimento desordenado e a falta de planejamento urbano facilitam a ocupação de regiões situadas nos arredores das pedreiras, provocando o fenômeno de "sufocamento" das mesmas e originando um quadro crescente de conflitos sociais.

O consumo de agregados constitui-se em um importante indicador da situação econômica e social de uma nação. Enquanto os EUA consomem, anualmente, cerca de 7,5 t por habitante de agregados e a Europa Ocidental, de 5 a 8 t por habitante/ano, no Brasil, o consumo está pouco acima de 2 t por habitante/ano. Mesmo dentro do país, os níveis de consumo de agregados têm diferenças significativas. O consumo no Estado de São Paulo chega a 4,5 t/hab/ano, enquanto que, em Fortaleza e Salvador, não atinge 2 t/hab/ano (Valverde, 2001).

Os efeitos ambientais estão associados, de modo geral, às diversas fases de exploração dos bens minerais, como à abertura da cava, (retirada da vegetação, escavações, movimentação de terra e modificação da paisagem local), ao uso de explosivos no desmonte de rocha (sobrepressão atmosférica, vibração do terreno, ultralançamento de fragmentos, fumos, gases, poeira, ruído), ao transporte e beneficiamento do minério (geração de poeira e ruído), afetando os meios como água, solo e ar, além da população local.

\section{3. Área de estudo}

A área de estudo abrange uma pedreira de diabásio, localizada dentro da malha de expansão urbana, na região noroeste do município de Campinas, Estado de São Paulo (Figura 1). A ocupação populacional ocorre nas porções leste e nordeste da pedreira. A nordeste da cava, distante $250 \mathrm{~m}$, encontram-se as construções comerciais mais próximas e, acerca de $800 \mathrm{~m}$, começam as primeiras casas do bairro residencial Vila Boa Vista.

\section{Identificação dos aspectos e impactos ambientais}

A atividade da pedreira em questão resume-se no decapeamento, desmonte da rocha com uso de explosivos, carregamento e transporte do minério e seu posterior beneficiamento, produzindo brita e “pó de pedra”, utilizados diretamente na usina de asfalto e como agregado na construção civil. Para identificar e avaliar os aspectos e impactos da pedreira, foram utilizados os dados de levantamento sismográfico obtidos durante o período de um ano de monitoramento dos desmontes, num total de 28 desmontes e 146 medições realizadas (Bacci, 2000). Os quadros apresentados foram elaborados segundo a metodologia utilizada na norma ISO 14001 (1996) e serviram, inicialmente, para identificar as principais fontes que geravam reclamações por parte da comunidade e, num segundo momento, como instrumento para avaliação de desempenho ambiental, dentro de um Sistema de Gestão Ambiental. As atividades descritas nos quadros 1, 2, 3 e 4 são as que ocorrem nas diferentes fases de lavra, no beneficiamento e na manutenção das instalações administrativas.

Segundo a NBR ISO 14001 (1996), o aspecto ambiental pode ser definido como "elemento das atividades, produtos e serviços de uma organização que pode interagir com o meio ambiente” e impacto ambiental como "qualquer mo- 


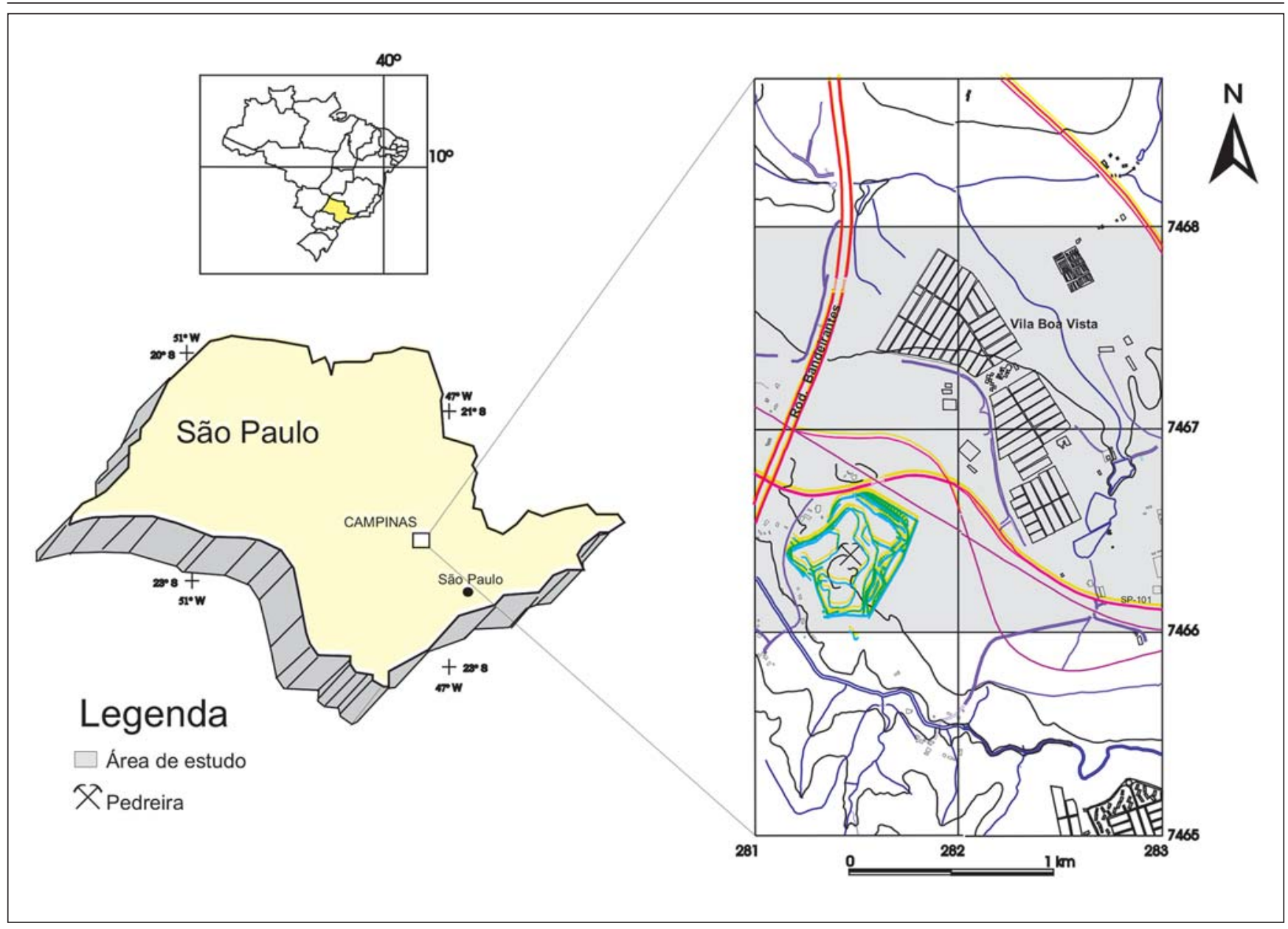

Figura 1 - Mapa de localização. Fonte: Folha Topográfica Campinas III e Jardim Santa Isabel, elaboradas pela Coordenadoria de Ação Regional, Divisão de Geografia do Plano Geográfico do Estado de São Paulo (1979), escala: 1:10.000.

dificação do meio ambiente, adversa ou benéfica, que resulte, no todo ou em parte, das atividades, produtos ou serviços de uma organização". Dessa forma, os quadros citados relacionam o tipo de atividade com os aspectos e impactos, positivos e negativos, que ela gera. Só assim é possível propor medidas de melhoria para solucionar os conflitos entre a atividade da pedreira e a comunidade.

Na identificação dos aspectos e dos impactos ambientais gerados pela empresa, foram considerados a produção do minério (extração, transporte e beneficiamento), as instalações administrativas, a oficina de manutenção e o refeitório.

Segundo Braga et al. (1996), os aspectos ambientais considerados nesse estudo foram: erosão, assoreamento, contaminação das águas superficiais e subterrâneas, impactos sobre a flora e fauna, instabilidade de taludes e encostas, mobilização de terra, poluição do ar, sonora e visual, ultralançamento de fragmentos, vibração do terreno e sobrepressão atmosférica.

Os Quadros 1, 2, 3 e 4 mostram os aspectos e impactos identificados nas diversas atividades da pedreira em questão. Entre os diversos impactos identificados, os que mais se destacaram associam-se ao desmonte de rocha com explosivos (sobrepressão, vibração do terreno e ruído), pois são os que causam maior desconforto à população do bairro residencial próximo à pedreira.

As principais fontes de sobrepressão numa detonação de bancada são: deslocamento da rocha, decorrente diretamente do deslocamento físico da rocha; vibrações na superfície rochosa, devido à reflexão das ondas sísmicas em faces livres, onde uma parcela da energia é transmitida como um pulso para o ar; escape de gases, decorrente do escape de gases pelas fraturas; ejeção do tampão, decorrente de gases saindo com a ejeção do tampão e do sistema de iniciação, como uso de cordel detonante e espoletas em superfície, não confinados.

Os efeitos da sobrepressão, na área de estudo, refletem-se nas estruturas civis através da vibração das paredes, janelas e objetos no interior das residências. Nos moradores, a percepção se expressa muito mais pelo susto no momento da detonação, do que pela interferência com as atividades diárias. Alguns moradores entrevistados não souberam expressar exatamente o que sentiram, mas todos manifestaram temor perante 0 evento da detonação. 
Quadro 1 - Principais aspectos e impactos ambientais da atividade de lavra a céu aberto.

\begin{tabular}{|c|c|c|}
\hline ATIVIDADES & ASPECTOS & IMPACTOS \\
\hline \multirow{3}{*}{$\begin{array}{l}\text { Decapeamento, envolvendo remoção da } \\
\text { cobertura superficial, deterioração da } \\
\text { cobertura vegetal e a formação de } \\
\text { pilhas de solo }\end{array}$} & \multirow{3}{*}{$\begin{array}{l}\text { Erosão, movimentação de terra e } \\
\text { assoreamento de córregos, alteração da } \\
\text { paisagem, flora e fauna locais }\end{array}$} & Esgotamento de recurso natural \\
\hline & & Afugento da fauna \\
\hline & & Modificação e destruição da vegetação nativa \\
\hline \multirow{3}{*}{ Perfuração das bancadas } & \multirow[b]{2}{*}{ Geração de ruído e poeira } & Poluição sonora \\
\hline & & $\begin{array}{l}\text { Perturbação das vizinhanças e exposição } \\
\text { ocupacional dos trabalhadores }\end{array}$ \\
\hline & $\begin{array}{l}\text { Utilização de equipamento de proteção } \\
\text { (máscara, luvas, botas, protetor de ouvidos) }\end{array}$ & $\begin{array}{l}\text { Diminuição dos riscos de acidentes e da } \\
\text { exposição ocupacional dos trabalhadores }\end{array}$ \\
\hline \multirow{3}{*}{ Carregamento dos furos com explosivos } & Possibilidade de acidentes & Explosão, riscos de vida \\
\hline & $\begin{array}{l}\text { Bom conhecimento geológico-estrutural da } \\
\text { jazida e da área de exploração }\end{array}$ & Redução de impactos ambientais \\
\hline & Treinamento e capacitação dos técnicos & Redução de riscos de acidentes \\
\hline \multirow{6}{*}{$\begin{array}{l}\text { Desmonte das bancadas com detonação } \\
\text { dos explosivos }\end{array}$} & $\begin{array}{l}\text { Geração e propagação de ondas sísmicas no } \\
\text { terreno e no ar (vibração e sobrepressão } \\
\text { atmosférica) }\end{array}$ & $\begin{array}{l}\text { Riscos de danos a construções civis, desconforto } \\
\text { à população vizinha, riscos de incidentes e de } \\
\text { vida }\end{array}$ \\
\hline & Ultralançamento de fragmentos & $\begin{array}{l}\text { Riscos de danos a construções civis e riscos a } \\
\text { vida humana }\end{array}$ \\
\hline & \multirow[b]{2}{*}{ Geração de ruído, fumos e gases } & Poluição sonora \\
\hline & & $\begin{array}{l}\text { Desconforto à população e riscos de incidentes e } \\
\text { intoxicação }\end{array}$ \\
\hline & $\begin{array}{l}\begin{array}{l}\text { Escorregamentos de taludes fora do setor de } \\
\text { desmonte }\end{array} \\
\end{array}$ & Riscos de acidentes \\
\hline & $\begin{array}{l}\text { Dimensionamento correto das cargas } \\
\text { explosivas e dos parâmetros do plano de } \\
\text { fogo (perfuração, carregamento, amarração } \\
\text { dos furos, limpeza da face, tempos de } \\
\text { retardo, etc) }\end{array}$ & $\begin{array}{l}\text { Redução das vibrações e da sobrepressão } \\
\text { atmosférica, não ocorrência de ultralançamentos } \\
\text { diminuição dos gases, além do fraturamento } \\
\text { ideal da rocha }\end{array}$ \\
\hline \multirow{2}{*}{$\begin{array}{l}\text { Armazenagem de explosivos e } \\
\text { acessórios de detonação }\end{array}$} & Riscos de explosão & Perdas materiais e de vidas, poluição do ar \\
\hline & Eficiência no armazenamento & Redução de riscos de acidentes \\
\hline Monitoramento ambiental & $\begin{array}{l}\text { Controle dos níveis de poluição respeitando } \\
\text { aqueles estabelecidos pelas normas técnicas } \\
\text { e legais }\end{array}$ & $\begin{array}{l}\text { Redução das emissões, minimização dos } \\
\text { impactos potenciais }\end{array}$ \\
\hline \multirow{2}{*}{$\begin{array}{l}\text { Carregamento e transporte do minério } \\
\text { até a britagem }\end{array}$} & Geração de poeira e ruído e emissão de gases & $\begin{array}{l}\text { Poluição do ar e sonora; Desconforto aos } \\
\text { trabalhadores da mina }\end{array}$ \\
\hline & Vazamentos de óleos/combustíveis/graxas & $\begin{array}{l}\text { Comprometimento do solo e das águas } \\
\text { superficiais }\end{array}$ \\
\hline \multirow{4}{*}{$\begin{array}{l}\text { Abertura de novas vias de acesso na } \\
\text { cava }\end{array}$} & $\begin{array}{l}\text { Processos erosivos e assoreamento dos } \\
\text { cursos d’água }\end{array}$ & Comprometimento dos recursos naturais \\
\hline & \multirow{2}{*}{$\begin{array}{l}\text { Geração de ruído, poeira e emissão de gases } \\
\text { produzidos pelas máquinas }\end{array}$} & Desconforto aos trabalhadores \\
\hline & & Poluição do ar e sonora \\
\hline & $\begin{array}{l}\text { Vazamentos de óleos/combustíveis/graxas } \\
\text { das máquinas }\end{array}$ & $\begin{array}{l}\text { Comprometimento do solo e das águas } \\
\text { superficiais }\end{array}$ \\
\hline \multirow{3}{*}{ Drenagem da cava } & \multirow{2}{*}{$\begin{array}{l}\text { Geração de efluentes, aporte de sedimentos } \\
\text { para os cursos d’água }\end{array}$} & Contaminação das águas superficiais \\
\hline & & $\begin{array}{l}\text { Comprometimento dos recursos naturais } \\
\text { superficiais }\end{array}$ \\
\hline & Consumo de energia & Utilização de recursos naturais \\
\hline \multirow{2}{*}{ Umidificação das vias de acesso } & \multirow{2}{*}{ Consumo de água } & Utilização de recursos naturais \\
\hline & & Redução da suspensão das partículas \\
\hline
\end{tabular}


Denise de La Corte Bacci et al.

Quadro 2 - Principais aspectos e impactos ambientais da atividade de beneficiamento.

\begin{tabular}{l|l|l}
\hline \multicolumn{1}{c|}{ ATIVIDADES } & \multicolumn{1}{c|}{ ASPECTOS } & \multicolumn{1}{c}{ IMPACTOS } \\
\hline Descarregamento do minério & Geração de poeira e ruído & $\begin{array}{l}\text { Poluição do ar e sonora, desconforto aos } \\
\text { trabalhadores }\end{array}$ \\
\hline \multirow{2}{*}{ Britagem da rocha } & Geração de poeira e ruído & $\begin{array}{l}\text { Poluição do ar e sonora, riscos de } \\
\text { doenças pulmonares e desconforto aos } \\
\text { trabalhadores }\end{array}$ \\
\cline { 2 - 3 } & Riscos de acidentes & Perdas de vida e materiais \\
\cline { 2 - 3 } & Consumo de energia & Utilização de recursos naturais \\
\cline { 2 - 3 } Umidificação das correias & Vibração dos equipamentos & Perdas de rendimento \\
\hline transportadoras & Consumo de água & $\begin{array}{l}\text { Utilização de recursos naturais, eventuais } \\
\text { acidentes, redução da suspensão das } \\
\text { partículas }\end{array}$ \\
\hline \multirow{2}{*}{ Transferência de materiais } & Escape/perda de material & $\begin{array}{l}\text { Riscos de acidentes, conforme o diâmetro } \\
\text { do minério }\end{array}$ \\
\cline { 2 - 3 } & Geração de poeira e ruído & $\begin{array}{l}\text { Poluição do ar e sonora, desconforto aos } \\
\text { trabalhadores }\end{array}$ \\
\hline \multirow{2}{*}{ Estocagem do produto } & $\begin{array}{l}\text { Geração de ruído, poeira e emissão } \\
\text { de gases produzidos pelas } \\
\text { máquinas }\end{array}$ & $\begin{array}{l}\text { Poluição do ar e sonora, intoxicação por } \\
\text { gases }\end{array}$ \\
\cline { 2 - 3 } & Perdas de material & $\begin{array}{l}\text { Contaminação das águas superficiais e } \\
\text { assoreamento de córregos próximos }\end{array}$ \\
\hline
\end{tabular}

No Brasil, o limite aceito para a sobrepressão é de $134 \mathrm{~dB}$, de acordo com ABNT(2004).

As vibrações de terreno são um subproduto inevitável de qualquer detonação. Na pedreira de diabásio, são causadas pelo uso dos explosivos, quebra e deslocamento da rocha. Os possíveis efeitos das vibrações, nas construções civis, se verificam através de trincas e rachaduras nas paredes e da vibração do terreno. Os moradores sentem a vibração do piso e das paredes e confundem os efeitos das vibrações do terreno com os da sobrepressão.

Os limites de vibração do terreno sugeridos pela NBR 9653 (2004) são divididos em três faixas, de acordo com a freqüência das ondas sísmicas, medidas através da velocidade de partícula: de 15 a $20 \mathrm{~mm} / \mathrm{s}$, para freqüências abaixo de 15 $\mathrm{Hz}$, de 20 a $50 \mathrm{~mm} / \mathrm{s}$, para freqüências entre 15 e $40 \mathrm{~Hz}$ e acima de $50 \mathrm{~mm} / \mathrm{s}$, para freqüências acima de $40 \mathrm{~Hz}$. No caso do Estado de São Paulo, a CETESB adota valor máximo de $4,2 \mathrm{~mm} / \mathrm{s}$, para a componente resultante, e 3,0 mm/s, para a componente vertical.

O ruído ocorre devido à detonação dos explosivos e pode ser ouvido no bairro residencial. Apesar de ocorrer uma ou duas vezes por semana, foi apontado como um dos impactos de desconforto, por assustar as pessoas em suas atividades diárias. Os maiores efeitos do ruído, no entanto, são observados no beneficiamento, devido à sua duração e continuidade e são mais uma preocupação ocupacional dos funcionários, não atingindo diretamente a comunidade.
Não foram levantados danos estruturais em residências durante o período do monitoramento sísmico, mas os moradores reclamam de desconforto no momento da detonação e associam problemas de rachaduras das paredes e trincas às atividades da pedreira.

\section{Discussão e conclusões}

Foram levantados os diversos aspectos e impactos ambientais da pedreira de diabásio, os quais podem servir de base para uma avaliação futura de desempenho ambiental da empresa e implementação de um sistema de gestão ambiental.

Observa-se que os impactos adversos mais significativos estão relaciona- 
Aspectos e impactos ambientais de pedreira em área urbana

Quadro 3 - Principais aspectos e impactos ambientais da atividade da oficina.

\begin{tabular}{|c|c|c|}
\hline ATIVIDADES & ASPECTOS & IMPACTOS \\
\hline $\begin{array}{l}\text { Circulação de veículos e } \\
\text { máquinas }\end{array}$ & $\begin{array}{l}\text { Emissão de gases e vazamento de } \\
\text { combustíveis, óleos e graxas }\end{array}$ & $\begin{array}{l}\text { Poluição do ar, contaminação do solo e dos } \\
\text { cursos d'água }\end{array}$ \\
\hline Armazenagem de óleo diesel & Vazamentos & Contaminação do solo e dos cursos d'água \\
\hline \multirow{4}{*}{ Abastecimento dos veículos } & \multirow{4}{*}{ Possibilidade de explosão } & Danos às instalações civis \\
\hline & & Perda /danos à integridade física \\
\hline & & Intoxicação em geral \\
\hline & & Poluição do ar \\
\hline \multirow{6}{*}{$\begin{array}{l}\text { Lubrificação, troca de óleo e } \\
\text { manutenção dos veículos }\end{array}$} & Vazamento de óleo e lubrificantes & Contaminação do solo e dos cursos d'água \\
\hline & Disposição dos resíduos (óleo e latas) & Redução do risco de contaminação \\
\hline & Reciclagem de material & Menor extração de matéria-prima \\
\hline & $\begin{array}{l}\text { Recuperação manufaturada de } \\
\text { lubrificantes }\end{array}$ & Menor extração de matéria-prima \\
\hline & \multirow{2}{*}{$\begin{array}{l}\text { Regulagem periódica dos motores e dos } \\
\text { veículos }\end{array}$} & Menor consumo de materiais de reposição \\
\hline & & Menor taxa de emissão de gases \\
\hline \multirow{5}{*}{ Lavagem de veículos } & Geração de efluentes & Poluição ambiental \\
\hline & $\begin{array}{l}\text { Geração de resíduos e embalagens } \\
\text { descartáveis }\end{array}$ & Poluição ambiental \\
\hline & Consumo de água & Utilização de recursos naturais \\
\hline & Consumo de energia & Utilização de recursos naturais \\
\hline & $\begin{array}{l}\text { Instalação de caixa cimentada coletora } \\
\text { de óleos o graxas e dos efluentes }\end{array}$ & $\begin{array}{l}\text { Prevenção na contaminação do solo e dos } \\
\text { cursos d'água }\end{array}$ \\
\hline \multirow{5}{*}{ Limpeza do local } & Geração de efluentes & Poluição ambiental \\
\hline & Consumo de água & Utilização de recursos naturais \\
\hline & Consumo de energia & Utilização de recursos naturais \\
\hline & Geração de resíduos e embalagens & Poluição ambiental \\
\hline & $\begin{array}{l}\text { Instalação de bacias de decantação ou } \\
\text { caixas coletoras dos efluentes }\end{array}$ & $\begin{array}{l}\text { Prevenção na contaminação das águas } \\
\text { superficiais }\end{array}$ \\
\hline
\end{tabular}

Quadro 4 - Principais aspectos e impactos ambientais das instalações administrativas.

\begin{tabular}{l|l|l}
\hline \multicolumn{1}{c|}{ ATIVIDADES } & \multicolumn{1}{|c}{ ASPECTOS } & \multicolumn{1}{c}{ IMPACTOS } \\
\hline \multirow{4}{*}{ Escritório e Refeitório } & Consumo de energia elétrica & Utilização de recursos naturais \\
\cline { 2 - 3 } & Consumo de água & Utilização de recursos naturais \\
\cline { 2 - 3 } & $\begin{array}{l}\text { Geração de efluentes e esgoto } \\
\text { sanitário }\end{array}$ & Contaminação das águas \\
\cline { 2 - 3 } & $\begin{array}{l}\text { Geração de resíduos e produtos } \\
\text { descartáveis e perecíveis }\end{array}$ & Poluição ambiental \\
\hline \multirow{2}{*}{ Limpeza } & Consumo de energia elétrica & Utilização de recursos naturais \\
\cline { 2 - 3 } & Consumo de água & Utilização de recursos naturais \\
\cline { 2 - 3 } & Geração de efluentes & Poluição ambiental \\
\cline { 2 - 3 } & Geração de resíduos e embalagens & Poluição ambiental \\
\hline
\end{tabular}


dos ao uso de explosivos no desmonte de rocha, os quais podem estender-se para áreas fora do domínio da pedreira, afetando, principalmente, o bairro residencial Vila Boa Vista, distante cerca de $800 \mathrm{~m}$ das frentes de lavra, a nordeste da cava.

A empresa ainda não possui um sistema de gestão ambiental e nem avaliações de desempenho, no entanto, algumas medidas de avaliação dos impactos foram tomadas, através do monitoramento das vibrações e da sobrepressão atmosférica. Os resultados do monitoramento mostraram que os valores de vibração obtidos nas residências não superam $2 \mathrm{~mm} / \mathrm{s}$, com freqüências de $50 \mathrm{~Hz}$ ou superior. Os valores de sobrepressão atmosférica atingem cerca de $100 \mathrm{~dB}$, o que gera um grande desconforto à população do bairro (Bacci \& Landim, 2001). Os resultados encontram-se abaixo dos níveis estabelecidos pelas normas brasileiras para tal atividade, tanto da NBR 9653 (2004) como a da CETESB D7.013 (1992) e também pelas normas internacionais (Bacci, et al., 2003a, 2003b) e não oferecem riscos de danos em estruturas civis. Constatou-se que grande parte dessas reclamações estão ligadas ao fato do desconhecimento, por parte dos moradores, das atividades e das medidas de minimização dos impactos empregadas pela empresa. A poluição do ar (geração de gases, fumos e poeira) está presente, tanto nas detonações, quanto no beneficiamento. Apesar de não ter sido quantificado, é um impacto de ordem local, restrito à área da pedreira e que está mais diretamente relacionado à questão de saúde ocupacional dos funcionários. Os impactos advindos das instalações administrativa e da oficina são também impactos locais e de ordem interna, não atingindo a comunidade.

Ultralançamentos de fragmentos não foram registrados e, devido ao plano de fogo utilizado, é um tipo de impacto de difícil ocorrência no local.

Como resultado imediato do monitoramento, algumas medidas de melhoria dos desmontes foram adotadas, como:
- Mudanças na direção das frentes de lavra (de nordeste para leste e sudeste) e abandono das frentes voltadas na direção da área residencial (norte).

- Aumento no tempo de detonação, com introdução de mais retardos de $42 \mathrm{~ms}$ entre linhas de furos e ajuste dos tempos de retardos entre furos, evitando superposição de cargas e aumento das vibrações.

- Manutenção de horários fixos das detonações com aviso à população local através de sinal sonoro.

Além de tais medidas de melhoria, novas ações poderiam ser adotadas pela empresa, no sentido de melhorar o relacionamento com a comunidade e evitar conflitos.

Algumas medidas pró-ativas que podem, facilmente, ser incorporadas às atividades da empresa são:

- Monitoramento contínuo dos desmontes e programas ativos para minimização de vibrações e sobrepressão, dado que estes são os impactos que mais afetam a comunidade local.

- Manutenção de todos os registros dos planos de fogo realizados, tanto para constar que a empresa tem controle sobre o uso dos explosivos, como para mostrar aos interessados os registros.

- Uso de insumos na operação de desmonte, de modo a minimizar os impactos ambientais, especialmente os propagados pela atmosfera na forma de ruído, sobrepressão e poeiras.

- Treinamento para os operadores vinculados às tarefas de desmonte, visando a habilitá-los na minimização dos impactos ambientais.

- Treinamento de, no mínimo, um funcionário da empresa para realizar monitoramentos freqüentes, dado que a empresa possui um sismógrafo de engenharia.

- Relacionamento com a comunidade através da contratação de consultores e serviços de vistoria e diagnóstico de danos em residências, de preferência terceirizados.
- Relacionamento com a comunidade através do estabelecimento de um registro de reclamações em formulário adequado, contendo, pelo menos, nome e endereço do reclamante.

- Divulgação das atividades e dos resultados de monitoramentos ambientais sempre que solicitada pela comunidade, a fim de confirmar a seriedade e transparência das atividades da empresa e das ações voltadas para prevenção, preservação do meio ambiente, refletindo na sua responsabilidade social.

De acordo com Worsey (2004), as boas relações públicas e a comunicação são as melhores ferramentas existentes, quando ocorrem conflitos. A empresa deve ser transparente, procurar ter um bom relacionamento com a comunidade e apresentar a ela como vem exercendo suas atividades, como se preocupa com o bem-estar e proteção da população, que existem limites aceitáveis de vibração do terreno e de sobrepressão e que trabalha dentro desses limites, que pratica o monitoramento dos impactos ambientais e está atenta ao desconforto causado pela atividade, mas que existem inúmeros estudos sobre os impactos gerados em pedreiras e que estes mostram que, uma vez respeitados os limites legais, a chance de ocorrer danos em suas residências é muito pequena. Através dessas atitudes, os conflitos são minimizados e a comunidade passa a entender o problema e a conviver com a atividade da pedreira de forma menos problemática.

$\mathrm{Na}$ área de estudo, apenas com algumas modificações nos desmontes, foi possível observar melhoria nas condições de relacionamento com a comunidade e diminuição das reclamações. Com o levantamento dos aspectos e impactos ambientais aqui apresentados, a empresa poderá adotar medidas pró-ativas, no sentido de prevenir futuros conflitos com a comunidade local e melhorar seu desempenho ambiental. 
6. Referências bibliográficas

ABNT ASSOCIAÇÃO BRASILEIRA DE NORMAS TÉCNICAS. Guia para avaliação dos efeitos provocados pelo uso de explosivos nas minerações em áreas urbanas. São Paulo: ABNT, 2004. 9 p.

ABNT ASSOCIAÇÃO BRASILEIRA DE NORMAS TÉCNICAS. Sistemas de gestão ambiental - Diretrizes gerais sobre princípios, sistemas e técnicas de apoio. NBR ISO 14.001. Rio de Janeiro: ABNT, 1996. 32 p.

BACCI, D.C. Vibrações geradas pelo uso de explosivos no desmonte de rochas: avaliação dos parâmetros físicos do terreno e dos efeitos ambientais. Rio Claro: Instituto de Geociências e Ciências Exatas, Universidade Estadual Paulista, 2000. V.1 (Texto) e V.2 (Anexos). (Tese de Doutorado).

BACCI, D.C., LANDIM, P. M. B. Statistical methods applied to the analysis of blasting vibrations in a diabase quarry at Campinas (SP) - Brazil. 28 ${ }^{\text {th }}$ Annual Conference on Explosives and Blasting Technique, Las Vegas (USA). ISEE Proceedings, 2001. v.I. p.265 - 279

BACCI, D.C., LANDIM, P. M. B., ESTON, S. M., IRAMINA, W.S. Principais normas e recomendações existentes para o controle de vibrações provocadas pelo uso de explosivos em áreas urbanas. Parte I. REM - Revista Escola de Minas. v.1, n.56, p.51-57, 2003a.

BACCI, D.C., LANDIM, P M B, ESTON, S M, IRAMINA, W. S. Principais normas e recomendações existentes para o controle de vibrações provocadas pelo uso de explosivos em áreas urbanas. Parte II. REM - Revista Escola de Minas. v.2, n.56, p.131 - 137, 2003b.

BRAGA T.O. et al. Auditoria ambiental, uma proposta para empreendimentos mineiros. Instituto de Pesquisas Tecnológicas, Boletim 69, São Paulo, 1996. $18 \mathrm{p}$.

BRASIL - Departamento Nacional da Produção Mineral. Anuário Mineral Brasileiro. 2001. Brasil/MME/SME/ DNPM, Brasília.

CETESB - COMPANHIA DE TECNOLOGIA DE SANEAMENTO AMBIENTAL - Norma D7.013 Mineração por explosivo. São Paulo: 1992. $7 \mathrm{p}$.

DE JORGE, F. N. Avaliação do desempenho ambiental - proposta metodológica e diretrizes para aplicação em empreendimentos civis e de mineração. São Paulo: Escola Politécnica, Universidade de São Paulo, 2001. 214p. (Tese de Doutorado).
INTERNATIONAL ORGANIZATION FOR STANDARDIZATION. Environmental management Environmental performance evaluation - Guidelines Norma ISO 14.031. S.L. 1999.

SÁNCHEZ, L.E. Os estudos de impacto ambiental como instrumentos de planejamento em pedreiras. SEMINÁRIO INTERNACIONAL SOBRE MINERAÇÃO EM ÁREAS URBANAS, São Paulo,. Anais..., São Paulo, DNPM/Pró-Minério. p.31-35. 1989.

SÁNCHEZ. L. E. Sistemas de gestão ambiental. Apostila didática de aulas. Curso ministrado na Escola Politécnica, Universidade de São Paulo. PósGraduação, ano letivo 2001.

VALVERDE, F. M. Agregados para a Construção Civil. Balanço Mineral Brasileiro, 2001. DNPM.

WORSEY, P.N. Blasting. In: WORSEY, P.N. DUTTA, S., PARAMESWARAN, K.(ed). Sustainable mining practices a global perspective. Balkema of Netherlands,. 2004. Cap. 9.

Artigo recebido em 08/09/2005 e aprovado em 08/02/2006.

\title{
REM - Revista Escola de Minas 70 anos divulgando CIÊNCIA.
}

\author{
$* * * * * *$ \\ REM: a mais antiga revista técnico- \\ científica do setor mínero-metalúrgico.
}

$* * * * * *$

www.rem.com.br

$* * * * * *$ 